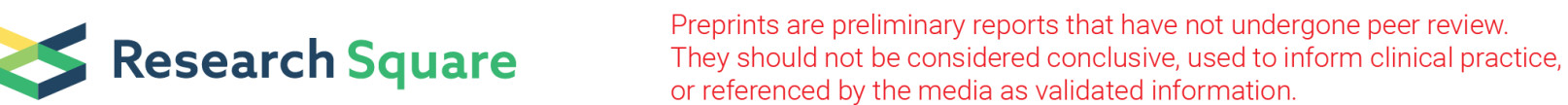

\section{Surfactants Efficiency on Pentachlophenol Contaminated Wastewater Enhanced by Pseudomonas Putida AJ 785569}

rim werheni Ammeri ( $\nabla$ rim.werheni@gmail.com )

CERTE: Centre de Recherche et des Technologies des Eaux de Borj Cedria https://orcid.org/0000-00033712-1386

yassin hidri

Olive University

\section{WAFA HASSRN}

University of Monastir Higher Institute of Arts and Crafts of Mahdia: Universite de Monastir Institut Superieur des Arts et Metiers de Mahdia

ines mehri

certe

\section{Nesrine khelifi}

CERTE: Centre de Recherche et des Technologies des Eaux de Borj Cedria abdenaceur Hassen

CERTE: Centre de Recherche et des Technologies des Eaux de Borj Cedria

\section{Research Article}

Keywords: Surfactants, wastewater, Pentachlorophenol, Pseudomonas putida, biofilm development

Posted Date: March 22nd, 2021

DOl: https://doi.org/10.21203/rs.3.rs-325862/v1

License: (a) (1) This work is licensed under a Creative Commons Attribution 4.0 International License. Read Full License

Version of Record: A version of this preprint was published at Archives of Microbiology on July 29th, 2021. See the published version at https://doi.org/10.1007/s00203-021-02486-1. 


\section{Abstract}

This study has objectives to assess the effects of some surfactants on (1) the bacterial growth, (2) PCP (800 mgL - 1 ) rate removal, and at last (3) biofilm development. Three different surfactants are used in this case as anionic (SDS), no anionic Tween 80 (TW80) and cationic (CTAB). The results improve that there was an adsorption of PCP by the bacterial cells of around $30 \mathrm{mg} . \mathrm{L}-1$ and PCP removal of around $720 \mathrm{mgL}-1$ after seven days. It appeared that the surfactant adding affected the bacterial growth and reach a maximum of PCP removal with SDS addition with a value $676.66 \mathrm{mg} \mathrm{L}-1$ in S.WW then CTAB and TW80. Biofilm formation in BHI with PCP showed a clear acceleration and enhancement of this activity with SDS addition. Besides, biofilm morphotype of selected strain appeared affected in form, density, and colour after different situations of stress caused by various surfactants or PCP.

\section{Full Text}

This preprint is available for download as a PDF.

\section{Figures}



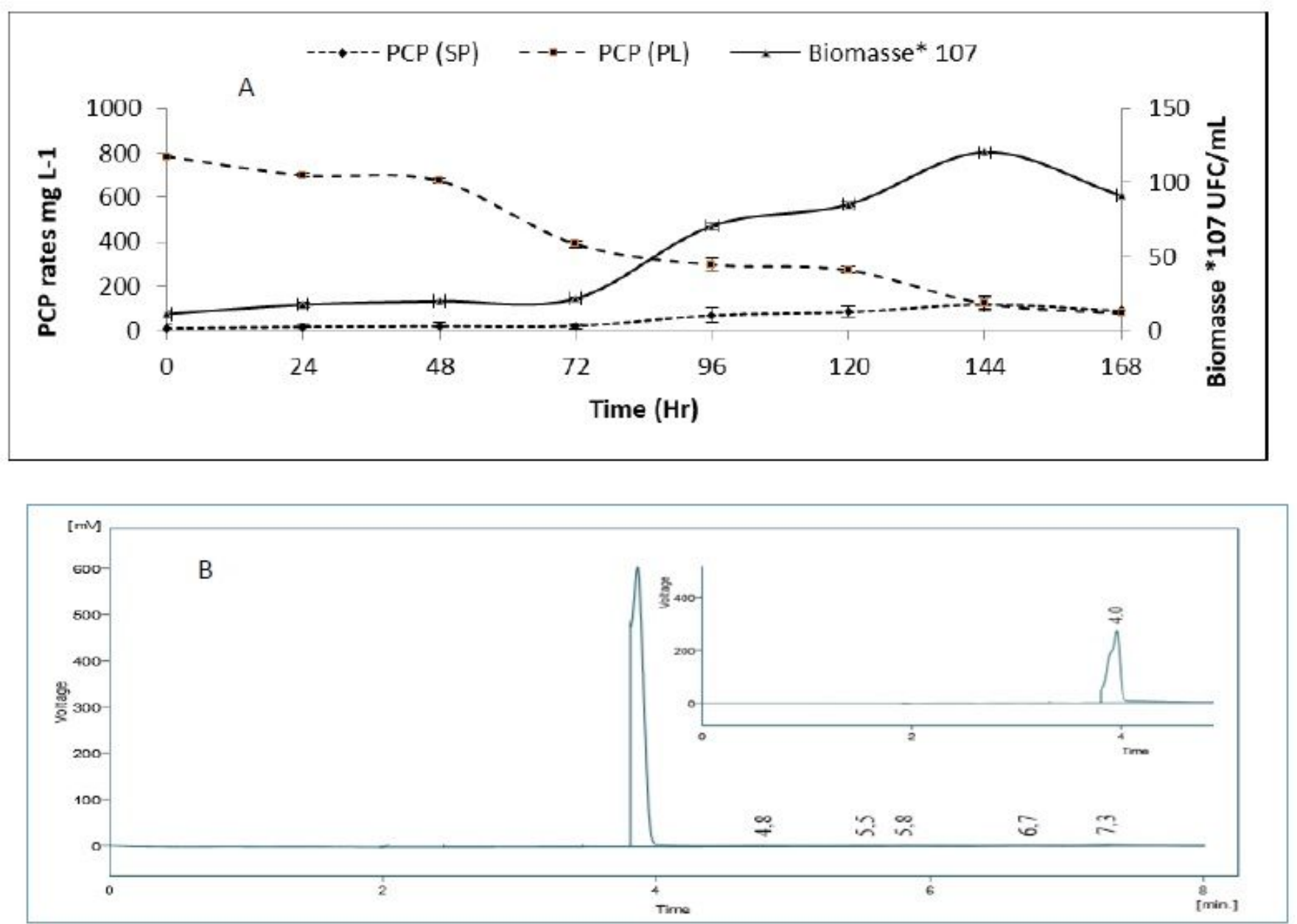

Figure 1

PCP (800 mg L-1) removal by P. putida AJ 785569 (A) in MSM in the supernatant (a)and adsorbed 455 (a), HPLC Chromatograph example at $30^{\circ} \mathrm{C}$ at first and seven days (B) of bioaugmentation treatment in MSM. 


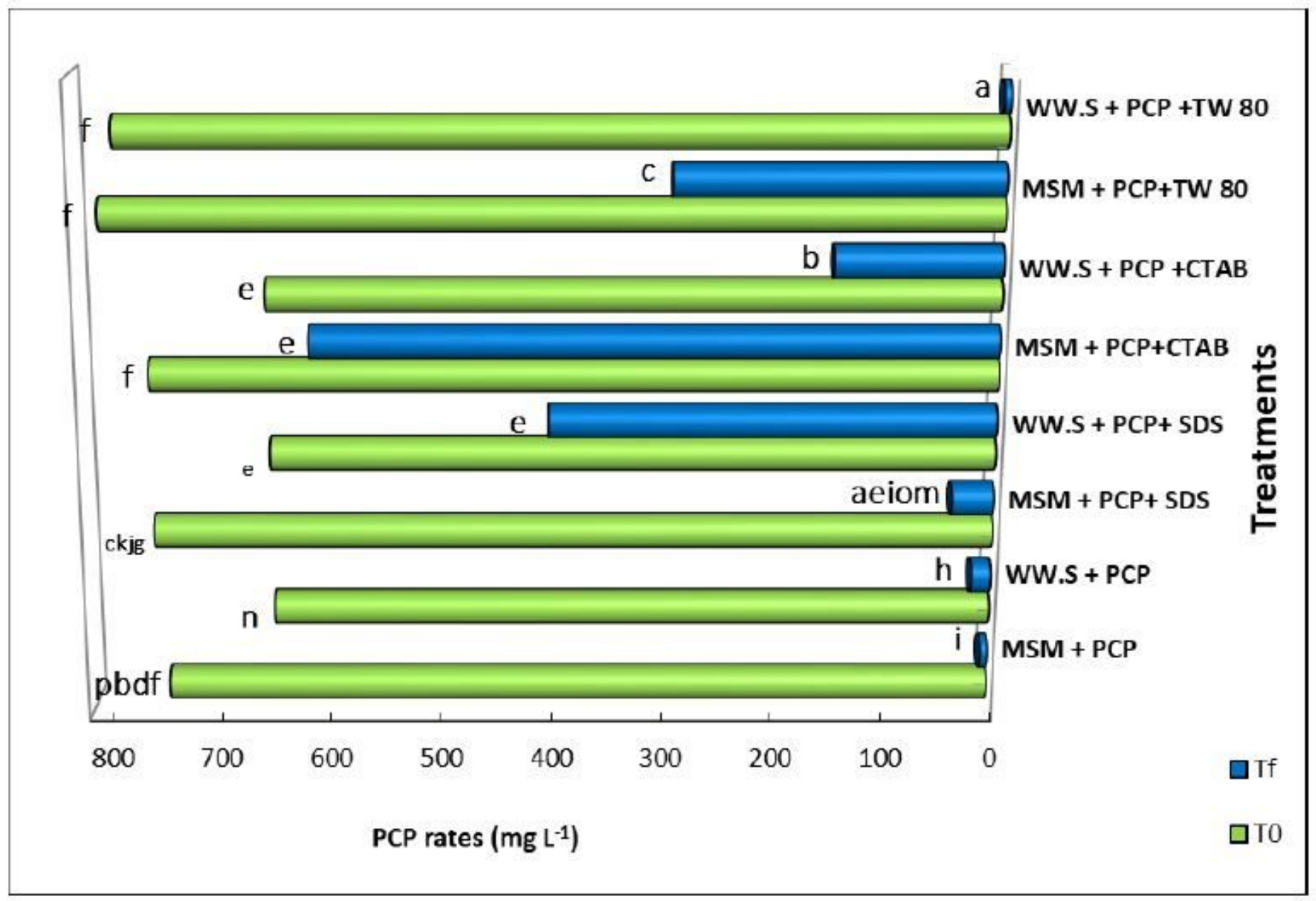

Figure 2

Evaluation of the bioaugmentation process of the Pseudomonas strain in the MSM and EUS by 462 monitoring the concentration of PCP $(800 \mathrm{mg} \mathrm{L}-1)$ after 7 days at $30^{\circ} \mathrm{C}$. SDS: sodium dodecyl sulfate; CTAB: 463 Bromure d'hexadécyltriméthyl ammonium; TW 80: Tween 80; PCP: Pentachlorophenol 

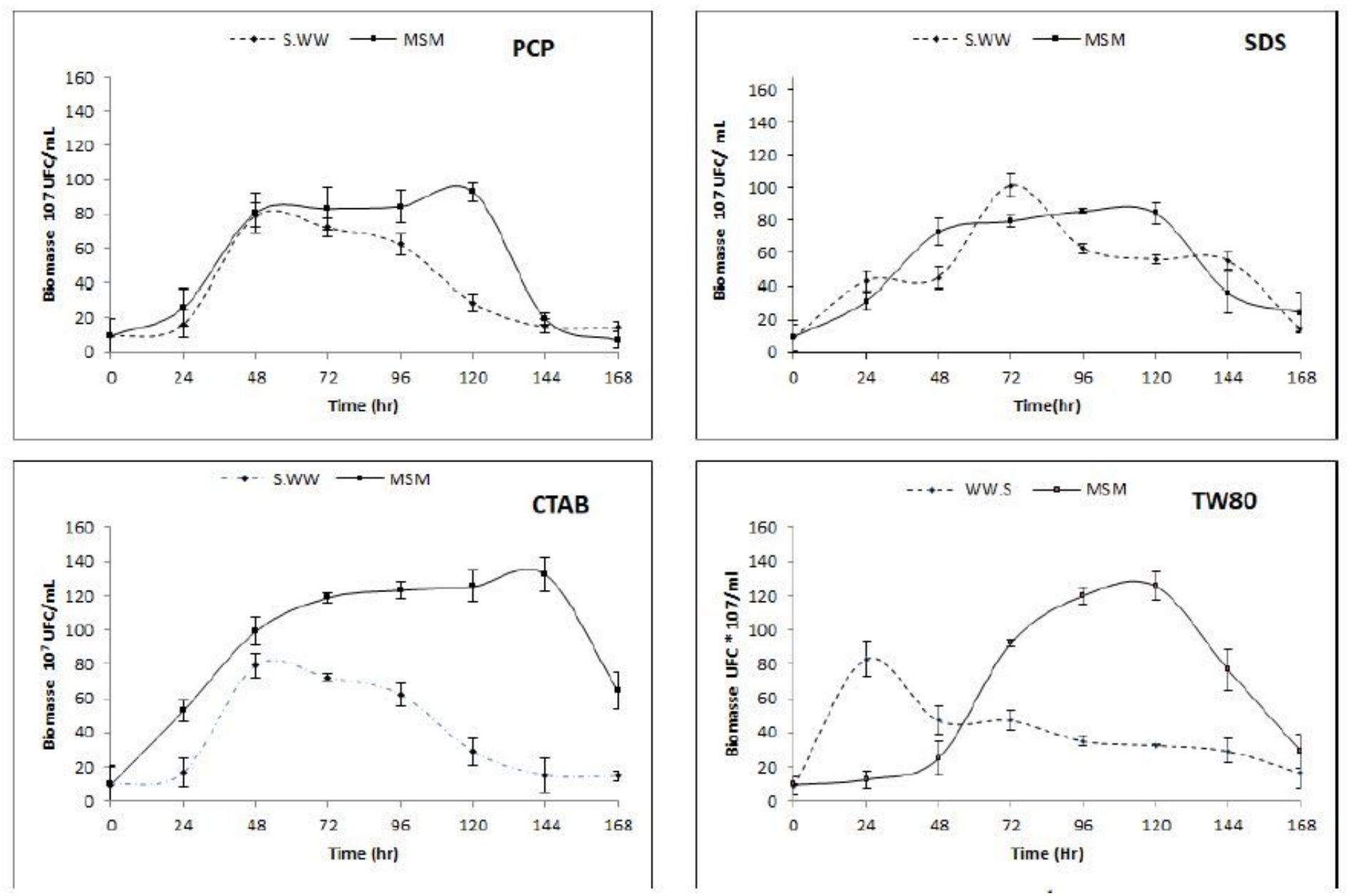

Figure 3

Monitoring of the chloride concentration (free chlorine) measurement (mg L-1) for each Pseudomonas 469 strain on the five treatments for seven days at $30^{\circ} \mathrm{C}$ in sterile wastewater and MSM. SDS: sodium dodecyl 470 sulfate; CTAB: Bromure d'hexadécyltriméthyl ammonium; TW 80: Tween 80; PCP: Pentachlorophenol 


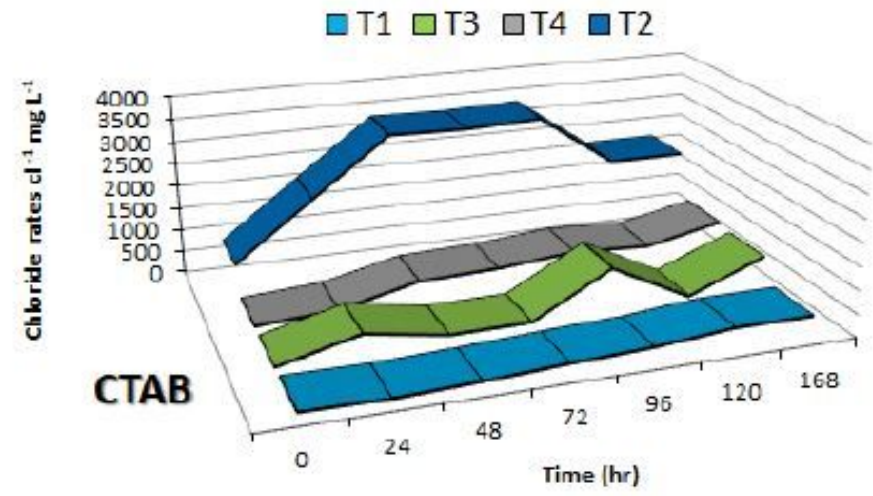

$\square \mathrm{T} 2 \square \mathrm{T} 1 \square \mathrm{T} 5 \square \mathrm{T} 6$

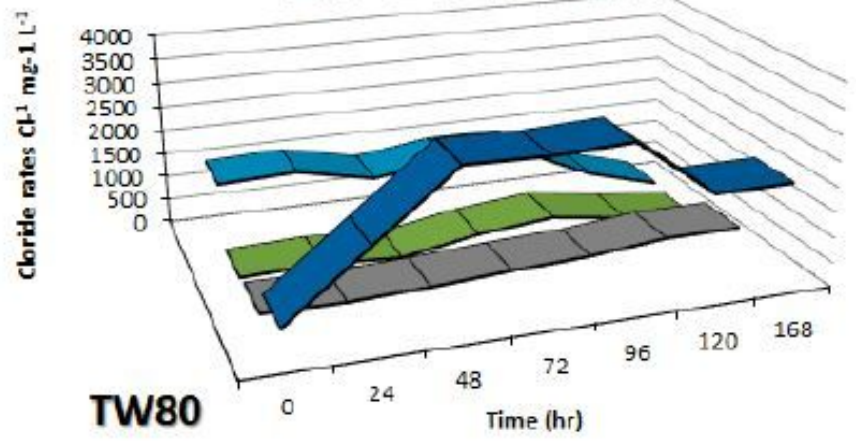

$\square T 2 \square T 1 \quad \square T 5 \quad \square T 6$

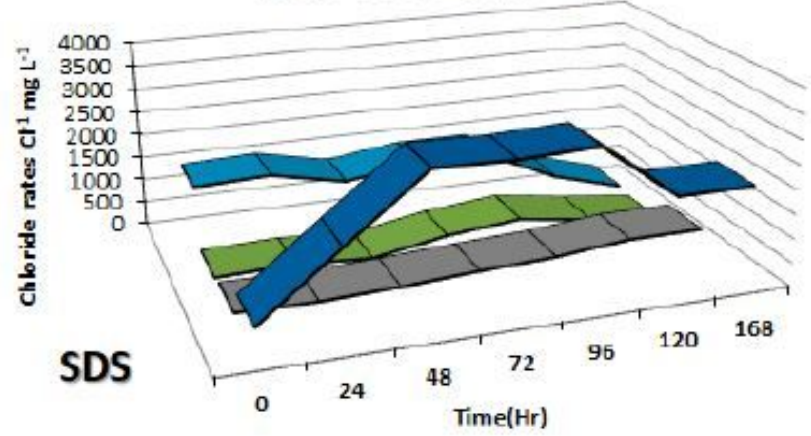

\section{Figure 4}

Monitoring of microbial growth in MSM (A) and wastewater (B) of exogenous Pseudomonas strains 477 on the five bioaugmentation treatments at a $\mathrm{T} 30^{\circ} \mathrm{C}$ and for 7 days at $150 \mathrm{rpm}$. SDS: sodium dodecyl sulfate; 478 CTAB: Bromure d'hexadécyltriméthyl ammonium; TW 80: Tween 80; PCP: Pentachlorophenol 


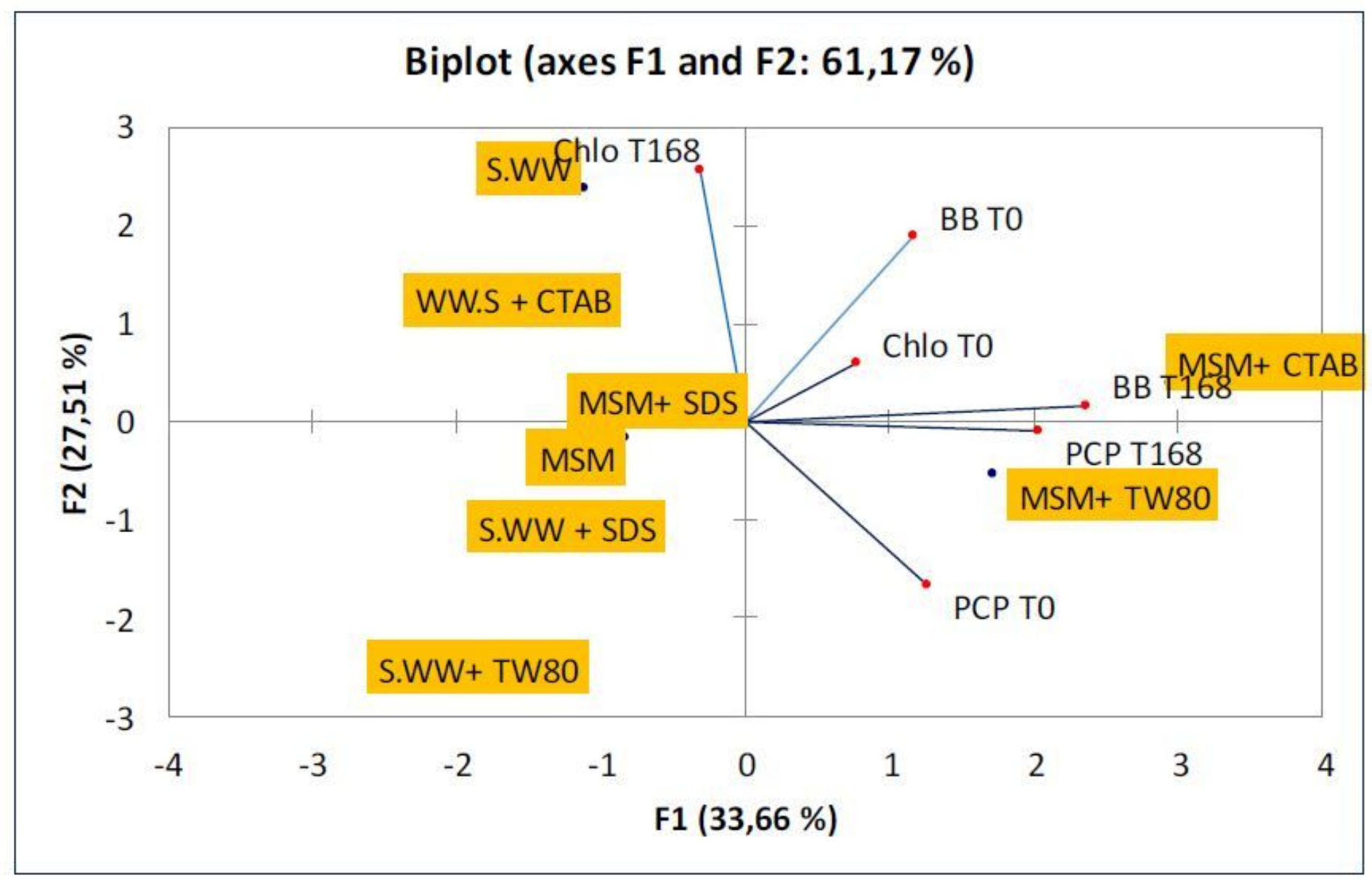

Figure 5

Principal component analysis of surfactant effect in bioaugmentation of PCP contaminated 483 wastewater. 484 SDS: sodium dodecyl sulfate; CTAB: Bromure d'hexadécyltriméthyl ammonium; TW 80: Tween 80; PCP: 485 Pentachlorophenol; Chlo: chloride; MSM: mineral saltmedium; BB: bacterial biomasse. 


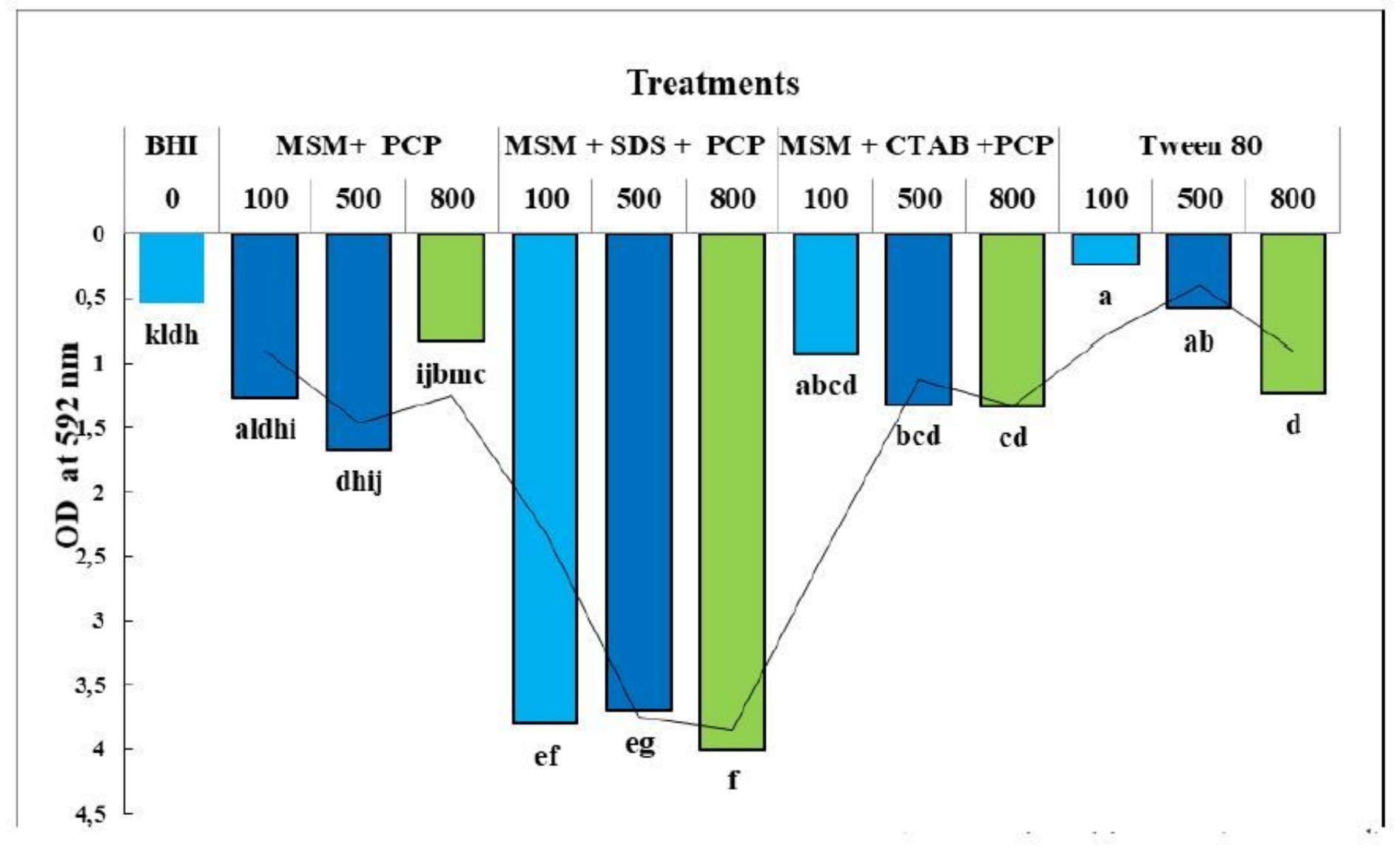

Figure 6

Example of biofilm formation in BHI agar medium artificially contaminated by PCP (100 mg. L-1) 489 supplemented with CRA and $20 \mathrm{mg}$. L-1 surfactant (SDS, CTAB, and TW 80 ) at $30^{\circ} \mathrm{C}$ during. SDS: sodium 490 dodecyl sulfate; CTAB: Bromure d'hexadécyltriméthyl ammonium; TW 80: Tween 80; PCP: 491 Pentachlorophenol. 


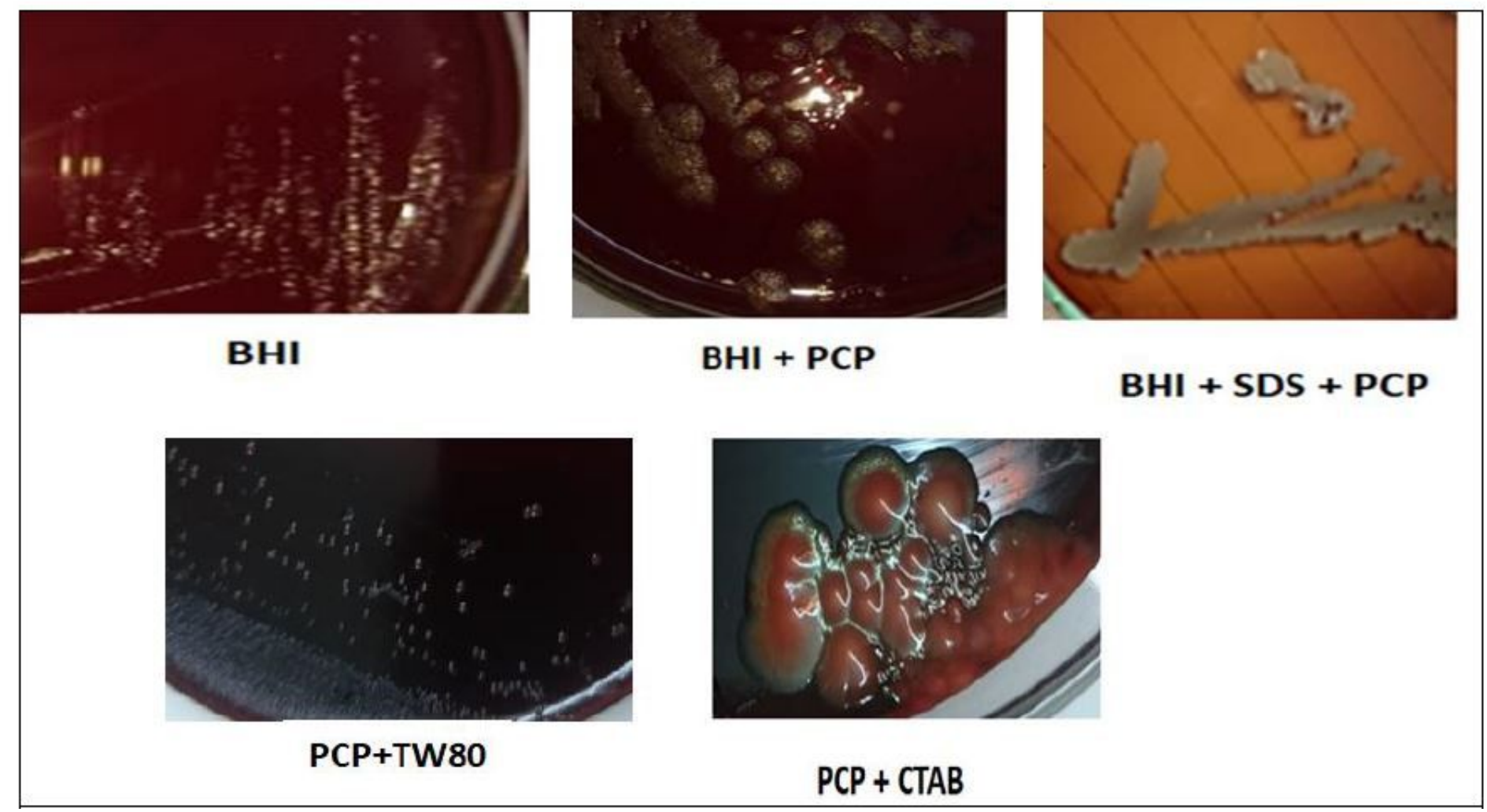

Figure 7

PCP effect in biofilm development at $100 \mathrm{mg}$. L-1 concentration and surfactant presence SDS, Tween 80, and 496 CTAB $(20 \mathrm{mg} . \mathrm{L}-1)$ after $24 \mathrm{hr}$ of incubation at $28^{\circ} \mathrm{C}$. Different lower case letters indicate significant differences 497 among treatment, at Duncan post-hoc test $(p<0.01)$

\section{Supplementary Files}

This is a list of supplementary files associated with this preprint. Click to download.

- GA.jpg 